\title{
Research on Visualization System Platform of Power Equipment Based on Internet of Things
}

\author{
Xuefeng Ning ${ }^{1, a}$, \\ ${ }^{1}$ Guangdong Power Grid Co., Ltd. Dongguan Power Supply Bureau, Zhushanwoling, Dongcheng District, Dongguan, Guangdong
}

\begin{abstract}
As an important basic industry to ensure the sustainable growth of the national economy, the power industry has a large amount of power equipment information. In order to solve the widespread status information dispersion, inefficient use of status information, and low visibility in the status management of power transmission and transformation equipment. Key technologies such as multi-source heterogeneous data information fusion and visualization of power grid panoramic state information based on 3D GIS, a visualized intelligent management and control system for power transmission and transformation equipment is developed, which can comprehensively realize the status monitoring and diagnosis of power transmission and transformation equipment. As well as early warning, it provides an important means for managers and frontline employees to carry out equipment status management, so that staff can quickly obtain key information and improve work efficiency.
\end{abstract}

\section{Introduction}

As an important basic industry to ensure the sustainable growth of the national economy, the power industry has a large amount of power equipment information, and the transmission and transformation equipment in good condition and stable operation is the foundation of a strong smart grid, which can effectively guarantee the economic development of the society.

With the rapid development of visualization technology, all walks of life have an increasing demand for information visualization, and the power industry is also working hard to use visualization technology in practical applications. Huang Xianming et al. [1] systematically monitor the operating status of the entire power grid through GIS technology, and display relevant line information, tower information, plant information, etc. on the geographic wiring diagram, thereby organically combining grid-related data with the ground information system Get up and display the operating status of the entire power grid on the map. Zheng J Y et al. ${ }^{[2]}$ took a threedimensional panorama for the substation, and then used relevant image processing technology to process the image to reproduce the real panorama of the substation for users, and realized functions such as patrol of the substation, equipment positioning, and equipment information viewing.

However, the rapid development of the power grid has brought about problems such as increased short-circuit capacity of the system and complex equipment management. Especially in recent years, there have been many grid accidents caused by high winds, lightning strikes, icing, and pollution. It is urgently needed Build a state management and control system for smart grids to conduct comprehensive and accurate monitoring, diagnosis and early warning of the state of power transmission and transformation equipment, effectively guarantee the safe operation of the grid, and improve the speed of response to emergencies. However, on the one hand, the currently built system is mainly for the condition monitoring of specific equipment and a single type of diagnosis and analysis for the later collected data, and the research on big data on the status of power transmission and transformation equipment is just in its infancy ${ }^{[3]}$; on the other hand, in the construction of the current information system of the power grid company, the status information is scattered in multiple 'information islands' with single functions such as PMS and SCADA. There is a lack of effective mining and utilization of massive data, and the visualization of equipment status is low, which severely restricts the effect and benefit of state management and control.

In response to the above research and problems, this paper proposes a visualization system for power equipment information, which applies multi-source heterogeneous data information fusion and a threedimensional GIS-based power grid in three aspects: transmission and transformation equipment status monitoring, status visualization and status intelligent diagnosis. Application of key technologies such as multi- 
source heterogeneous data information fusion and 3D GIS-based power grid panoramic state information visualization ${ }^{[4]}$, completed the development and application of the state visualization system for power transmission and transformation equipment (hereinafter referred to as 'visualization system'), which can realize the visual display of power transmission and transformation equipment and query and early warning functions. Provide basis for equipment condition maintenance and improve the intelligent level of grid operation.

\section{Fusion method of multi-source heterogeneous data}

\subsection{Data acquisition}

The visualization system platform of power transmission and transformation equipment status monitoring needs to integrate multiple systems horizontally. At this stage, it includes PMS data, online monitoring system data, GIS data, meteorological system data, and video monitoring system data (Table 1). The data interface method preferentially adopts Web Service ${ }^{[5]}$, and at the same time, it is integrated with the actual situation.

Tab.1 Data sources and access objects for visualization system

\begin{tabular}{|c|c|}
\hline Data Source & Access Object \\
\hline $\begin{array}{l}\text { Meteorological } \\
\text { Information System }\end{array}$ & $\begin{array}{l}\text { Weather forecast information, weather cloud } \\
\text { map }\end{array}$ \\
\hline Production MIS system & $\begin{array}{l}\text { Ledger data of power transmission and } \\
\text { transformation equipment, mainly including } \\
\text { equipment nameplate, technical parameters, } \\
\text { equipment change management information } \\
\text { and other data; equipment inspection, } \\
\text { maintenance and operation and maintenance } \\
\text { information, mainly including defect records, } \\
\text { fault records, operation and maintenance } \\
\text { records, operation and maintenance records } \\
\text { and other data; Ledger information; test data; } \\
\text { status maintenance information; defect } \\
\text { information }\end{array}$ \\
\hline $\begin{array}{l}\text { On-line monitoring } \\
\text { system for power } \\
\text { transmission and } \\
\text { transformation } \\
\text { equipment }\end{array}$ & $\begin{array}{l}\text { Transformer equipment status monitoring } \\
\text { parameters, including oil temperature and oil } \\
\text { pressure, oil chromatogram, partial discharge, } \\
\text { ground current, bushing dielectric loss } \\
\text { capacitance, OLTC status, vibration } \\
\text { spectrum, etc.; GIS equipment status } \\
\text { monitoring parameters, including partial } \\
\text { discharge, gas density and micro Water } \\
\text { content, gas leakage, gas composition, etc.; } \\
\text { overhead line monitoring parameters, mainly } \\
\text { including ice coating, micro-weather, } \\
\text { temperature (sag), wind deviation, galloping, } \\
\text { vibration, tower tilt, etc.; cable monitoring } \\
\text { parameters, mainly temperature and Partial } \\
\text { Discharge }\end{array}$ \\
\hline $\begin{array}{c}\text { Capacitive equipment } \\
\text { online monitoring } \\
\text { system } \\
\end{array}$ & $\begin{array}{l}\text { Dielectric dissipation factor and capacitance } \\
\text { of capacitive equipment }\end{array}$ \\
\hline $\begin{array}{l}\text { Video surveillance } \\
\text { system }\end{array}$ & $\begin{array}{l}\text { Substation } \\
\text { information }\end{array}$ \\
\hline
\end{tabular}

The implementation of the interface includes the following.

(1) Web Service call. For the condition monitoring information that needs to be further processed by the visualization system platform of the power transmission and transformation equipment condition monitoring, and the condition monitoring has provided the data of the service interface, the data is obtained through service invocation, the principle is to take it and use it at any time. The equipment status is stored in the database of the visualization system.

(2) Grid spatial data acquisition. The grid spatial data is more complex, including structured data such as coordinate axes, latitude and longitude, and unstructured data such as images and text. According to different data types, structured data interface and unstructured data interface are used to obtain data from the system.

(3) Unstructured data acquisition interface. For unstructured data such as documents, audio, surveillance video, and pictures obtained from inspections, the relevant files are directly read and called through the general file transfer protocol, and subsequent cleaning, conversion and other processing tasks are performed.

(4) Structured data acquisition interface. For conventional relational database data, it is directly obtained using programming interfaces such as JDBC/ODBC. For data with a higher security level, the business system provides the interface, which is acquired through the data acquisition/conversion device or actively pushed by the business system, and the relevant data is sent on the enterprise message bus, the data acquisition/conversion device monitors the message bus to acquire data.

(5) Page embedding integration. For the status monitoring information that does not require further processing on the visualization system platform, and the status monitoring has provided the corresponding module page, the corresponding function page is called through the URL.

\subsection{Data processing method}

Due to the multiple information sources, different structures, and various attributes of the acquired data, it is necessary to preprocess and clean the data in the data quality management process. Data cleaning focuses on the detection and separation of noise through clustering methods, and the detection and filling of missing values of key features. When evaluating the quality of multi-source heterogeneous data from different data levels and different index dimensions, the big data quality index system used is shown in Figure 1.\$ 


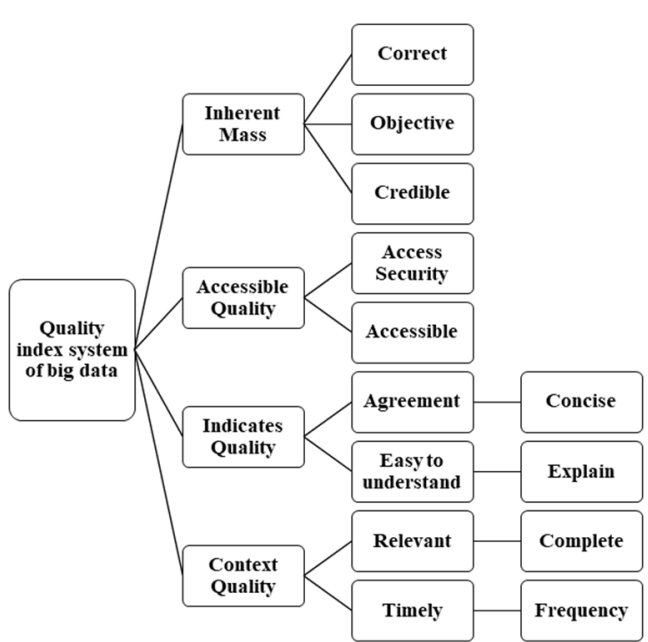

Fiq.1 Quality index system of big data

Data conversion mainly uses operations such as data standardization and data attribute construction to further improve data quality and improve the accuracy and performance of data mining or data stream mining ${ }^{[6]}$. Data generalization uses conceptual hierarchies, replacing lowlevel 'raw' data with high-level concepts, and generalizing the original data in the database into statistically significant metadata aggregated at the conceptual level that users are interested in.

\subsection{Data storage and retrieval technology}

The multi-source heterogeneous data of the power equipment condition monitoring visualization system platform based on the Internet of Things is stored using the Hadoop 2.0 distributed file system architecture, to provide big data application support and meet the technical requirements of the visualization system for big data management. When the amount of data reaches the PB level, it can process the data from the production management system, scheduling information data, GIS geographic data, meteorological data, inspection image data and other system equipment status information, sensor equipment operation information, video monitoring information, and various for structured and unstructured data of this kind of business, the read response time for structured data is not higher than $0.2 \mathrm{~s}$, and the read response time for unstructured data is not higher than $5 \mathrm{~s}$.

The visual system of power equipment state monitoring is divided into perception layer, network layer and application layer. The interactive content between these three layers is divided into message flow and data flow, and the processing of data flow is controlled through message flow. The interaction between the three layers is event-driven, which ensures that the collected data can be instantly displayed to the user interface.

In order to perform complex data query, a multi-level comprehensive index is established to improve the retrieval performance of evaluation data with similar characteristics. The first-level index adopts a multidimensional R-tree structure ${ }^{[7]}$ to realize key data feature dimensions. According to the classification rules of nontraditional geographic information, the cleaned data objects are divided into multiple subspaces, and each subspace corresponds to a node on the R tree. The non-leaf nodes in the tree store the Minimum Bounding Rectangle (MBR) of all subtrees, and the leaf nodes store the MBR corresponding to each spatial object. The second-level and lower indexes use object clustering based on adjacent density. The relative density of clustered objects in the same cluster is close to each other, and the relative density of objects in different clusters is low, so as to achieve the purpose of clustering objects.

\section{Visual display technology of 3D GIS}

The power equipment condition monitoring visualization system platform of the Internet of Things builds a display system based on 3D GIS, which embeds the 3D visualization effects of lines and substations, so that staff can quickly browse the power grid in the office and view information such as line corridors and substation layouts. At the same time, it is connected to the video surveillance system, and can be superimposed on professional tiles such as wind, thunder, ice, and dirty areas to display equipment status information in multiple dimensions.

First of all, to create and manage 3D data, Arc Globe 10.0 provides a standard editing environment, allowing the creation and maintenance of GIS elements with height information, and mainly provides the following functions.

(1) Add Arc Globe layer: The layer type of Arc Globe is different from ArcMap. There are 3 types of layers in Arc Globe, which are Elevation layers, Draped layers and Floating layers.

(2) Coordinate conversion: The conversion prompt window (Geographic Coordinate Systems Warning) can customize the coordinate system to be converted, or choose the default coordinate system WGS84.

(3) Add terrain data: In the Add Data Wizard window, the terrain data will be loaded to Elevation layers as the elevation data source in the 3D scene, and the terrain data will be added as an elevation data source of the sphere elevation layer After entering the Globe, you can see the terrain changes after loading.

(4) Add vector data: Basic vector data can be divided into point, line, and area data. Right-click on the data to open the Layer Properties dialog box. In Symbiology, you can set vector symbolization and two-dimensional integrated symbol modification.

(5) Add model data and components: Street view components, including towers, lines, and substations, are stored as point files in the feature class. Use 3DS Max to model and implement according to the schedule. According to the actual collected drawings, picture materials and data size, establish the model of the simulation object in the substation model list at a ratio of 1:1 and optimize the model. Set the texture, material, and texture of each model. Location, organize the model as a whole, easy to manage and use. The 3DS format is one of the formats exported by 3DS Max. The 3DS threedimensional virtual model library can be flexibly implanted into various application systems such as GIS systems and visualization systems as required, as shown in Figure 2. 


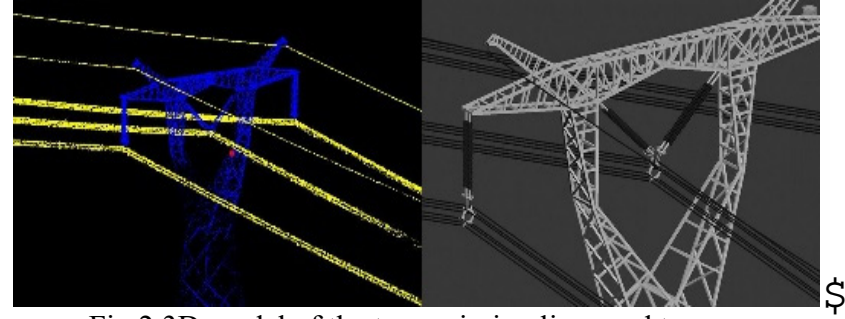

Fig.2 3D model of the transmission lines and towers

\section{Visualization system architecture of power transmission and transformation equipment status}

\subsection{Deployment architecture}

The visualized intelligent management and control system of power transmission and transformation equipment status is deployed in the computer room of the provincial company. The headquarters of the company, the provincial power research institute, the provincial maintenance company, and the power supply companies of various cities access the system through the IE browser. The deployment architecture of the visualized system platform for power equipment condition monitoring is shown in Figure 3.

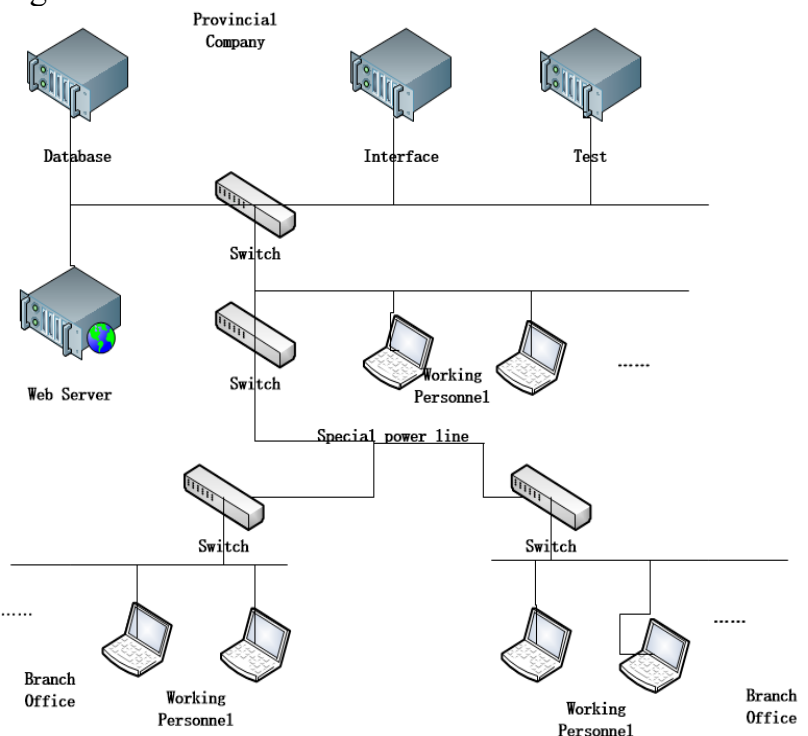

Fig.3 Deployment architecture of the visualization intelligent management and control system

Figure 4 shows the security protection architecture of the power equipment state monitoring visualization system platform.

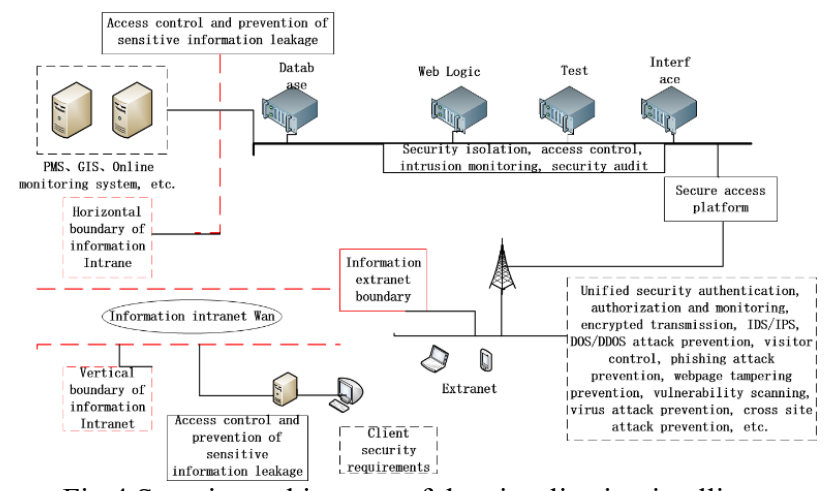

Fig.4 Security architecture of the visualization intelligent management and control system

\subsection{Integrated architecture}

The visualization system platform for power equipment condition monitoring is loosely coupled and integrated with related systems through a data exchange bus or data center that crosses the safety zone. It adopts an SOA architecture and publishes on the bus in a service manner. The model and interaction standards follow IEC61970/61968-CIM And SG-CIM specifications. The system integration architecture is shown in Figure 5.

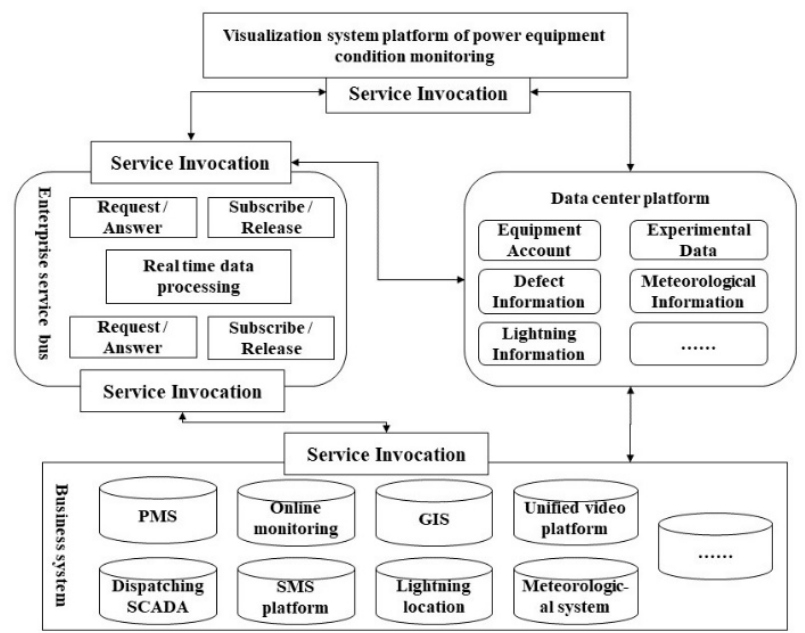

Fig.5 System integration architecture

The data source integration method of the power equipment condition monitoring visualization system platform is listed in Table 2.

Tab.2 Data source integration mode of the visualization

\begin{tabular}{|l|l|l|l|}
\hline Data source & Data name & $\begin{array}{l}\text { Access } \\
\text { method }\end{array}$ & $\begin{array}{l}\text { Data usage } \\
\text { scenario }\end{array}$ \\
\hline $\begin{array}{l}\text { Dispatch } \\
\text { SCADA } \\
\text { display }\end{array}$ & $\begin{array}{l}\text { Regional load } \\
\text { data } \\
\text { information, } \\
\text { switch status } \\
\text { information }\end{array}$ & Call service & $\begin{array}{l}\text { Real-time } \\
\text { display }\end{array}$ \\
\hline PMS & $\begin{array}{l}\text { Organization } \\
\text { and personnel } \\
\text { information, } \\
\text { equipment } \\
\text { ledger, } \\
\text { equipment } \\
\text { defects, } \\
\text { equipment } \\
\text { evaluation } \\
\text { information, } \\
\text { etc. }\end{array}$ & Data center & $\begin{array}{l}\text { Real-time } \\
\text { display and } \\
\text { diagnostic } \\
\text { data support }\end{array}$ \\
\end{tabular}




\begin{tabular}{|l|l|l|l|}
\hline GIS & $\begin{array}{l}\text { Geographic } \\
\text { information, } \\
\text { power grid } \\
\text { model }\end{array}$ & $\begin{array}{l}\text { Secondary } \\
\text { component } \\
\text { integration }\end{array}$ & $\begin{array}{l}\text { Related } \\
\text { equipment } \\
\text { information, } \\
\text { display } \\
\text { equipment } \\
\text { status } \\
\text { evaluation } \\
\text { results, early } \\
\text { warning } \\
\text { information, } \\
\text { online } \\
\text { monitoring }\end{array}$ \\
information, \\
etc.
\end{tabular}

The system operation interface is shown in Figure 6 and Figure 7.

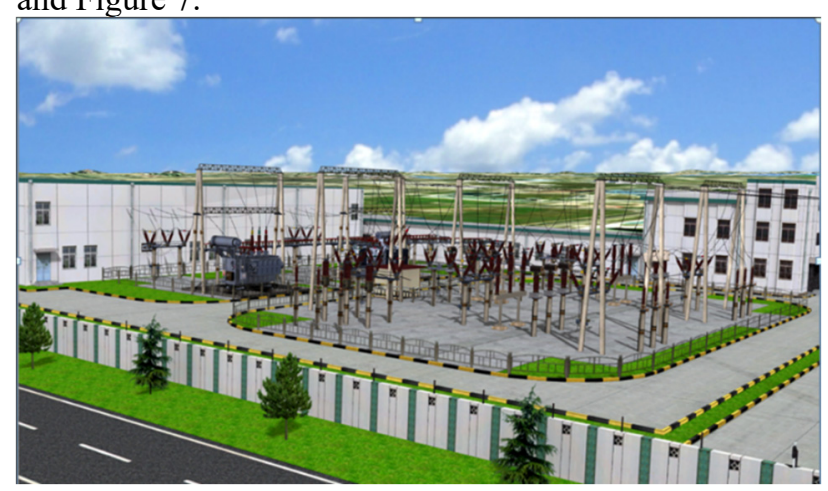

Fig.6 System operation interface

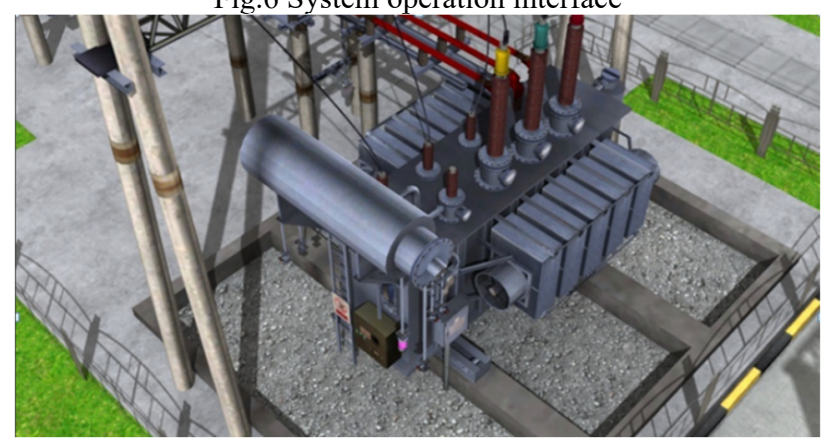

Fig.7 System operation interface

\section{Conclusion}

The power equipment condition monitoring visualization system platform based on the Internet of Things realizes the high integration and fusion of the status information of the power transmission and transformation equipment, realizes the status monitoring, diagnosis and early warning of the transmission line equipment, and improves the equipment information display, status evaluation, and risk warning The level of intelligence, such as condition monitoring and production management, has become an important means for managers and front-line employees to carry out equipment condition management. The application of this system platform has realized a profound change in the state management of power transmission and transformation equipment from offline information collection and analysis to panoramic, real-time, multidimensional, and intelligent state management and control, and fully realizes the full life cycle management of grid assets for power supply companies under the new power reform situation, Cost reduction and efficiency enhancement have important practical significance.\$

\section{References}

1. Huang Xianming, Liu Jiunv.Application and implementation of WebGIS-Network Geographic Information System [,]. Agricultural Mechanization Research, 2004, 7 (4): 243-244

2. Zheng J Y, S hi M .Scanning depth of route panorama based on stationary blur $[\mathrm{J}] \cdot$ International Journal of Computer Vision 2008, 78(2/3):169-186.

3. ZHANG Bo-wen, YAN Chun-yu, BI Jian-gang, et al. Research on the architecture of electrical equipment status early warning system based on big data[J]. Electric Power Information and Communication Technology, 2016, 14(12): 2632.

4. Tang Yiping. Perception technology and application of Internet of things -- intelligent panoramic video perception [M]. Beijing: Electronic Industry Press, 2013

5. ZHANG Xi-zhe, LV Tian-yang, ZHANG Bin. Modeling complex collaboration network for service-oriented software based on execution behaviors[J]. Journal of Software, 2016, 27(2): 231-246.

6. CHEN Ai-dong, LIU Guo-hua, FEI Fan, et al. Association rules mining algorithm for uncertain data with the uniform distribution[J]. Journal of Computer Research and Development, 2013, 50(S1): 186-195.

7. YU Yan, LIN Wei-hua, TAN Xiao-jun. Spatial index method based on R-tree[J]. Computer Engineering, 2012, 36(12):30-32.

8. Zhang Jianmin, $\mathrm{Xu}$ Aichun, Li Haixiang. An automatic engineering configuration system for substation automation based on SVG/XMLICM 
[J].Automation of Electric Power Systems, 2004, 28(14):54-57.

9. LI Yaping, YAO Jianguo, HUANG Haifeng, et al. Application of SVG in the dispatching automation system of power network[J]. Automation of Electric Power Systems, 2005,29(23):80-83.

10. Raheli Enrica,Wu Qiuwei,Zhang Menglin,Wen Changyun. Optimal coordinated operation of integrated natural gas and electric power systems: A review of modeling and solution methods[J]. Renewable and Sustainable Energy Reviews,2021,145.

11. A. A. Pavlov,E. S. Soboleva. Anti-Frictional CopperFluoroplast Coating for Parts of Power Equipment[J]. Chemical and Petroleum Engineering,2021(prepublish). 